\title{
Venire contra factum proprium non valet
}

SUMARIO: I. INTRODUCCIÓN. II. SIGNIFICADO DEL PRINCIPIO Y SU APLICACIÓN EN EL DERECHO ADMINISTRATIVO. III. REQUISITOS PARA LA APLICACIÓN DE LA DOCTRINA DE LOS ACTOS PROPIOS. 1. El «acto» o conducta: elemento objetivo. 2. El carácter «propio» del acto: elemento subjetivo. 3. La actuación contradictoria y sus consecuencias jurídicas. IV. ACTOS PROPIOS Y PRINCIPIO DE LEGALIDAD DE LA ADMINISTRACIÓN. V. PARA TERMINAR.

\section{INTRODUCCIÓN}

No abundan en nuestra doctrina del Derecho administrativo (del Derecho público, en general) los estudios sobre la llamada «doctrina de los actos propios». En realidad, salvo error u omisión, no existe ninguna monografía que, desde la perspectiva iuspublicista, aborde la cuestión. Tan sólo pueden encontrarse algunos artículos ya lejanos en el tiempo de grandes maestros de nuestro Derecho administrativo, que abordan el principio que prohíbe ir contra los actos propios por su relación con el régimen de la revisión de los actos administrativos y el recurso de lesividad ${ }^{1}$; con posterioridad se hallan referencias en algunos estudios, también de prestigiosos juristas, sobre el principio de la buena fe en el Derecho administrativo ${ }^{2}$; y, por último, en algunos

${ }^{1}$ L. López Rodó, «Presupuestos subjetivos de la aplicación del principio que prohíbe ir contra los propios actos», en $R A P, 9$, 1952, pp. 11 y ss.; E. GARCÍA DE ENTERRÍA, «La doctrina de los actos propios y el sistema de lesividad», $R A P, 20,1956$, pp. 69 y ss.

${ }^{2}$ J. GONZÁleZ PÉREZ, El principio general de la buena fe en el Derecho administrativo, Madrid, $1983\left(1^{\text {a }}\right)$, pp. 117 y ss.; F. SAINZ MORENO, «La buena fe en las relaciones de la Administración pública con los administrados», RAP, 89, 1979.

Documentación Administrativa / nº. 263-264 (mayo-diciembre 2002) 
trabajos más recientes sobre el principio de protección de la confianza legítima $^{3}$, sin perjuicio de otras alusiones tangenciales en trabajos de distinto objeto ${ }^{4}$.

Esos estudios ponen de relieve que la doctrina de los actos propios, de muy antiguo ascendiente, se elabora en el Derecho privado ${ }^{5}$, de donde pasa al Derecho público, aunque no sin las «necesarias matizaciones», como ha declarado el propio Tribunal Constitucional ${ }^{6}$. También destacan la directa relación de la doctrina con el principio de buena fe, del que constituiría una manifestación, o con el de confianza legítima, sin olvidar su engarce con el principio de seguridad jurídica. Y, con atención a la doctrina civilista, algunos de ellos se adentran en su definición, requisitos y efectos ${ }^{7}$. En total, ni siquiera un centenar de páginas doctrinales dedicadas al argumento.

Sin embargo, la escasez de estudios teóricos contrasta con la frecuente utilización por los órganos de la Jurisdicción Contencioso-Administrativa del apotegma venire contra factum proprium non valet para la resolución de los recursos y la fundamentación de las sentencias. Basta un somero examen de los repertorios jurisprudenciales para comprobarlo. Además, la invocación del principio se realiza en casos muy distintos y con muy diferentes manifestaciones y efectos, de manera que es difícil deducir de la jurisprudencia conclusiones precisas. Ya hace casi medio siglo, GARCíA DE ENTERRÍA señalaba que «la doctrina de los actos propios se utiliza generalmente con una inespecífica, y aún más, grosera imprecisión, y esto no sólo en el Derecho administrativo, donde es notorio que su invocación por los autores y por la ju-

${ }^{3}$ F. A. Castillo Blanco, La protección de confianza en el Derecho administrativo, Madrid, 1998; J. GARCía LuENGO, El principio de protección de la confianza en el Derecho administrativo, Madrid, 2002, en especial pp. 128 y ss.

${ }^{4}$ Por ejemplo, F. Velasco Caballero, Las cláusulas accesorias del acto administrativo, Madrid, 1996, pp. 246 y ss.

${ }^{5}$ Por todos, L. DíEZ-PICAZO y PONCE DE LEÓN, La doctrina de los propios actos, Barcelona, 1963.

${ }^{6}$ STC 73/1988, de 21 de abril (f.j. 5). Se trata, en cualquier caso, de un obiter dicta destinado a rechazar la alegación del principio en el recurso de amparo: «...la llamada doctrina de los actos propios o regla que decreta la inadmisibilidad de venire contra factum proprium, surgida originariamente en el ámbito del Derecho privado, significa la vinculación del autor de una declaración de voluntad generalmente de carácter tácito al sentido objetivo de la misma y a la imposibilidad de adoptar después un comportamiento contradictorio, lo que encuentra su fundamento último en la protección que objetivamente requiere la confianza que fundadamente se puede haber depositado en el comportamiento ajeno y la regla de la buena fe que impone el deber de coherencia en el comportamiento y limita por ello el ejercicio de los derechos subjetivos. Quiere ello decir que aunque tal doctrina puede ser aplicable a las relaciones jurídicas regidas por el Derecho administrativo y por el Derecho público en general como ha venido reconociendo la jurisprudencia del Tribunal Supremo, sólo puede serlo con las necesarias matizaciones que no la desvíen de los principios rectores que constituyen su fundamento último, la protección de la confianza y la protección de la buena fe (...) si el juego de tales principios puede encontrar alguna conexión con la idea de seguridad jurídica, no tiene ninguna con el derecho de los ciudadanos a la igualdad ante la ley...».

${ }^{7}$ El análisis más detallado es de GoNZÁLEZ PÉREZ en la obra citada. 
risprudencia descarga de ordinario de la necesidad de mayores análisis, sino también en el campo, más depurado técnicamente, del Derecho civil» ${ }^{8}$. Aquí nos interesa lo que sucede en la práctica (judicial) del Derecho administrativo sin que nos sirva de consuelo lo común del problema. Pero hay que decir que, décadas después, la cita no ha perdido nada de actualidad. Valga una muestra.

Sentencias hay que encuentran el fundamento del principio de irrevocabilidad de los actos administrativos favorables en venire contra factum proprium, de manera que se infringe este principio cuando se desconocen los límites legales de la revocación o revisión de oficio (por ejemplo, SSTS de 23 y 28 de marzo de 1993, 15 de enero y 3 de marzo de 1999, etc.).

También y desde antiguo se apela a los «actos propios» para rechazar que la Administración pueda alegar la inadmisibilidad de un recurso interpuesto por un ciudadano siguiendo las erróneas indicaciones de aquélla sobre los recursos procedentes (STS de 6 de marzo de 1978 y un buen número de resoluciones posteriores; últimamente, por ejemplo, STSJ Madrid de 21 de septiembre de 1999).

No es insólito que se plantee la autovinculación de la Administración a sus circulares e instrucciones internas como manifestación de la prohibición de ir contra los propios actos (STS de 7 de octubre de 1991). Pero también a veces se aduce el mismo principio para sancionar el incumplimiento por la Administración de un reglamento u ordenanza propio (STSJ de Asturias de 22 de diciembre de 1997; STSJ Cataluña de 24 de febrero de 1998).

De manera semejante hay sentencias que relacionan con dicha prohibición el incumplimiento por la Administración de un contrato, convenio o concierto por ella firmado (STS de 11 de julio de 1997, relativa a un concierto entre dos entidades públicas que una de ellas pretende desconocer).

La doctrina de los actos propios puede servir también como fundamento de la prohibición de reformatio in peius, en materia sancionadora o tributaria (STSJ La Rioja de 17 de enero de 2000).

Asimismo, esa doctrina se aduce para alegar la vinculación de la Administración a los informes evacuados en las consultas urbanísticas, si bien la jurisprudencia deniega tal vinculación, en aplicación del Derecho urbanístico estatal, hoy supletorio (SSTS de 30 de diciembre de 1996, 10 de abril de 2000 y un largo etcétera). Cosa distin-

${ }^{8}$ Op. cit., pp. 71-72, con cita de PUIG BRUTAU, referida al Derecho civil: «es inseguro el criterio seguido para la aplicación de dicho principio [de los actos propios]. En lugar de quedar el mismo adscrito a unos supuestos de hecho concretos y detallados, todavía flota en la mayor imprecisión, y con frecuencia se limita a servir de complemento a los argumentos que se esgrimen sobre la base de conceptos diferentes». 
ta es, por cierto, lo que deriva de la legislación urbanística reciente de algunas Comunidades Autónomas .

A veces se utiliza la referencia a los actos propios para anular una resolución que desconoce o no tiene en cuenta hechos reconocidos en informes de la misma Administración obrantes en el expediente (SAN de 20 de junio de 2001), o para anular actos definitivos que contradicen otros de trámite del mismo procedimiento (por ejemplo, STSJ de Navarra de 5 de junio de 2000, que declara ilegal la exclusión de una solicitante en el procedimiento en concurrencia de autorización de una oficina de farmacia acordada en el acto definitivo porque la propia Administración había admitido su instancia, aunque presentada fuera de plazo).

También se alude al principio de que tratamos para determinar si la Administración queda o no vinculada por hechos reconocidos en certificaciones propias o aceptados como ciertos en otros procedimientos (STS de 20 de febrero de 1992), aunque no siempre se entiende -más bien al contrario- que las certificaciones surten los efectos de los actos propios (STS de 4 de marzo de 2002, por ejemplo).

En algunas sentencias se considera como contrario a los actos propios apartarse del precedente legal ( STSJ Cataluña de 28 de noviembre de 1997, STSJ Madrid de 2 de febrero de 2002, STSJ Murcia de 6 de abril de 2001).

Incluso alguna resolución aplica el mismo principio para justificar la prohibición de un órgano de la Administración de recurrir contra actos de la misma (STSJ Castilla-La Mancha de 28 de diciembre de 1999).

En fin, incurre en la prohibición del venire contra factum proprium la Administración que alega en juicio contra su estimación parcial del recurso de reposición, defendiendo íntegramente el acto originario (STS de 4 de marzo de 2002).

Eso por lo que se refiere a la prohibición de la Administración de obrar contra sus propios actos. Pero otras muchas resoluciones judiciales aplican la doctrina de los actos propios para desestimar pretensiones de los ciudadanos recurrentes y ello, con frecuencia, como una objeción previa que excusa entrar en el examen de la legalidad del acto impugnado.

Supuesto característico es la negativa a enjuiciar actos cualificados de un procedimiento que no se impugnaron en su día por quien recu-

\footnotetext{
${ }^{9}$ Por ejemplo, el art. 148 de la Ley 5/1999, de 8 de abril, de Urbanismo de Castilla y León, atribuye carácter vinculante a los informes emitidos por el Ayuntamiento y la Comunidad Autónoma en virtud de consulta a efectos del desarrollo del suelo urbanizable «no delimitado» mediante planes parciales. También ha de tenerse en cuenta, en materia tributaria, lo dispuesto en el art. 107.4 y 5 LGT, que regulan los supuestos en que es vinculante la contestación a las consultas tributarias.
} 
rre contra la resolución definitiva. La jurisprudencia liga en estos casos con frecuencia la doctrina de los actos propios con la excepción de acto consentido. Así, en el caso de quien impugna el resultado de una oposición o concurso con fundamento en la ilegalidad de las bases de la convocatoria que no recurrió en su momento (SSTS de 19 de septiembre de 1994, 20 de marzo de 1995, 16 de junio de 1997, 24 de marzo de 1998; STSJ Baleares de 4 de octubre de 2000, STSJ Castilla-La Mancha de 27 de diciembre de 2000, STSJ Andalucía-Granada de 13 de marzo de 2001, STSJ Galicia, de 9 de mayo de 2001, SAN de 5 de abril de 2001 y muchas más), o de quien pretende la anulación de la adjudicación de un contrato en virtud de la ilegalidad de un pliego de cláusulas al que se aquietó (SSTS de 30 de septiembre de 1999, 8 de octubre de 1999 y 9 de febrero de 2001, entre otras muchas).

Lo mismo ocurre a veces cuando se impugnan condiciones impuestas por la Administración para la emisión de un acto administrativo favorable, una vez dictado éste (SSTS de 19 de enero de 1994 y 16 de abril de 1997), supuesto denominado de los «actos administrativos por sometimiento» ${ }^{10}$, que sin embargo no recibe una respuesta judicial unívoca (por ejemplo, STS de 23 de octubre de 1991, que anula por ilegal la condición previa de pago de reparcelación económica para otorgar la licencia urbanística en recurso interpuesto por el adjudicatario de la licencia; en sentido similar STS de 28 de septiembre de 2001, que declara ilegal y anula el pago de cantidad en concepto de cesión de aprovechamiento realizado por el recurrente como condición para obtener la licencia).

También se funda en los «actos propios» la desestimación del recurso contra una cláusula de un convenio o acuerdo firmado por el recurrente (por ejemplo, STSJ Madrid, de 22 de septiembre de 2000, relativa a un acuerdo sindical de funcionarios).

Igualmente, con el mismo fundamento, se desestima la pretensión de un funcionario de desdecirse de la renuncia formalizada ante la Administración (SSTS de 23 de enero y 28 de mayo de 2001) o se considera conforme a Derecho la obligación impuesta por la Administración a un funcionario de acceder al puesto de trabajo que ganó por concurso, pese a haber renunciado a él al conocer el resultado de dicho concurso (SAN de 31 de mayo de 1999).

Los ejemplos podrían multiplicarse. Como puede verse, hay una utilización indiscriminada de la doctrina de los actos propios, inclusive en casos cuya solución responde con facilidad a otro tipo de fundamentos jurídicos. Como recientemente se ha apuntado, los Tribunales usan dicha doctrina «como un comodín» ${ }^{11}$. A veces, más bien, como

${ }^{10}$ F. Velasco Caballero, op. cit., p. 246.

${ }^{11}$ J. GarCía Luengo, op. cit., p. 132. 
un «cómodo» expediente que ahorra al Juez o a la Sala, según señalaba GARCÍA DE ENTERRÍA, profundizar en «mayores análisis».

Por eso -y por las consecuencias injustas a que puede llevar semejante hábito- resulta oportuno acometer de nuevo un intento de depuración doctrinal del concepto y de sus elementos. Tarea que se ofrece aquí, bien es cierto, con no poco escepticismo acerca de su utilidad práctica, dada la presión sobre el juez que deriva de la necesariamente masiva y acelerada producción en serie de resoluciones judiciales; esto es, de un sistema judicial que, saturado por la insaciable demanda de tutela efectiva y obsesionado por la productividad y la estadística, apunta más a la cantidad que a la calidad.

\section{SIGNIFICADO DEL PRINCIPIO Y SU APLICACIÓN EN EL DERECHO ADMINISTRATIVO}

La prohibición de venire contra factum proprium supone que no es lícito que un sujeto de Derecho adopte unilateralmente decisiones o formule pretensiones incompatibles con la conducta que ha mantenido con anterioridad en sus relaciones con otro y con la que ha generado una situación jurídica de algún modo favorable a éste. Se trata de una exigencia de coherencia en el comportamiento, esto es, en las relaciones jurídicas, que enlaza directamente con el principio de buena fe y el de confianza legítima.

Por consiguiente, la aplicación de la regla implica tres condiciones: a) que un sujeto determinado haya realizado o venga observando cierta conducta, ya se trate de un acto o de varios, ya sean expresos o tácitos, pero que en todo caso sean reveladores de un determinado o comportamiento; b) que con posterioridad realice alguna actuación o mantenga una pretensión distinta, con eficacia jurídica; c) que exista contradicción o incompatibilidad objetiva entre una y otra conducta.

No obstante, conviene añadir alguna precisión más, pues el principio no es predicable de cualquier tipo de acto o actuación. Según una sentencia reciente (Sentencia del Tribunal Supremo, Sala Tercera, de 4 de marzo de 2002, Pte.: Segundo Menéndez Díaz):

«Tiene dicho la jurisprudencia de esta Sala (sentencias, entre otras, de 23 de junio de 1971, 24 de noviembre de 1973, 26 de diciembre de 1978, 25 de noviembre de 1980, 26 de septiembre de 1981, 2 de octubre de 2000) que la aplicación del principio que prohíbe ir contra los propios actos requiere, respecto de éstos, que se trate de actuaciones realizadas con el fin de crear, modificar o extinguir algún derecho, definiendo una situación jurídica, de manera indubitada. En la misma línea, la jurisprudencia de la Sala de lo Civil del Tribunal Supremo tiene declarado (así, por todas, la sentencia de 9 de mayo de 2000: 
'el principio de derecho que veda ir contra los propios actos (nemo potest contra proprium actum venire) como límite al ejercicio de un derecho subjetivo o de una facultad, cuyo apoyo legal se encuentra en el artículo 7.1 del Código Civil, que acoge la exigencia de buena fe en el comportamiento jurídico, y con base en el que se impone un deber de coherencia en el tráfico sin que sea dable defraudar la confianza que fundadamente se crea en los demás, precisa para su aplicación la observancia de un comportamiento (hechos, actos) con plena conciencia de crear, definir, fijar, modificar, extinguir o esclarecer una determinada situación jurídica, para lo cual es insoslayable el carácter concluyente e indubitado, con plena significación inequívoca del mismo, de tal modo que entre la conducta anterior y la pretensión actual exista una incompatibilidad o contradicción, en el sentido que, de buena fe, hubiere de atribuirse a la conducta anterior; y esta doctrina (...) no es aplicable cuando la significación de los precedentes fácticos que se invocan tiene carácter ambiguo o inconcreto (...) o carece de la trascendencia que se pretende para producir el cambio jurídico».

Esto es, estamos hablando no de actuaciones indirectas, ocasionales o poco claras, desmentidas por hechos posteriores, sino de actuaciones conscientes y de significado manifiesto, capaces de generar esa situación de confianza que se defrauda con el acto o pretensión posterior. No es aceptable, por tanto, para aplicar el principio invocar cualquier acción del sujeto contra quien se aplica, pues actuaciones lejanas, de significado o finalidad distinta o simplemente aleatorias carecen de la eficacia suficiente para configurarse como «acto propio» a estos efectos. Y así es tanto para la jurisprudencia civil como contencioso-administrativa. Más adelante, sin embargo, hemos de detallar el concepto.

La precisión apuntada no excluye, de todas formas, que estemos ante un principio de contenido muy amplio y susceptible de muy distintas manifestaciones. Tanto en Derecho privado como en Derecho público, pues es indudable que el principio se aplica también en el ámbito del Derecho público, aun con las matizaciones de que se tratará y que han sido recordadas por el Tribunal Constitucional.

Ahora bien, las manifestaciones no pueden ser exactamente las mismas en Derecho privado y en Derecho público. Y ello por la sencilla razón de que las relaciones jurídicas administrativas se rigen por principios en parte distintos. En concreto, la vinculación más intensa de la Administración al principio de legalidad y sus poderes de decisión unilateral ejecutoria finalizados a la tutela objetiva de los intereses públicos (la llamada autotutela administrativa, en suma), con todas sus consecuencias dogmáticas, excluyen y desplazan en muchos casos la aplicación de la doctrina de los actos propios, formulada originariamente en función del principio de autonomía de la voluntad, mientras 
que en otros obligan a matizarla. De ahí la necesidad de una depuración técnica de esa doctrina en el ámbito del Derecho administrativo.

Por ejemplo, la doctrina de los actos propios nada tiene que ver con las modificaciones que la Administración introduce en sus reglamentos o en sus instrumentos de planificación, ya que a estos efectos la Administración es titular de un ius variandi reconocido por el ordenamiento. Podemos afirmar, junto con la jurisprudencia del Tribunal Supremo (por todas, Sentencia de 10 de diciembre de 1999) que la doctrina se aplica tan sólo a actos en sentido estricto y no a normas. Lo contrario supondría, como es obvio, en palabras de la citada Sentencia, «limitar las facultades de innovación que los reglamentos posteriores puedan introducir respecto de la regulación de los precedentes, pues lo contrario conduciría al resultado de la petrificación del orden jurídico». Lo mismo puede decirse de los planes, urbanísticos u otros (STS de 14 de junio de 2000), y ello sin perjuicio de la responsabilidad patrimonial que pudiera derivar de su modificación, que es cuestión ajena a la doctrina de los actos propios.

De la misma manera que es ajeno a este principio el supuesto de contravención de reglamentos y planes por la Administración y el órgano autor de los mismos, problema que tiene respuesta en el principio de inderogabilidad singular, que es manifestación del principio de legalidad. Todas estas cuestiones han de abordarse con instrumentos y técnicas propias del Derecho público, sin que la doctrina de los actos propios resulte aplicable.

Tampoco es correcto (ni necesario) aludir a la doctrina de los actos propios para examinar o no la conformidad a Derecho de las normas reglamentarias con eficacia retroactiva. Éste es un problema distinto, que tiene en nuestros Derecho un tratamiento específico como es sabido (art. 9.2 CE), pues aquí está en juego el principio de seguridad jurídica y no, salvo excepción, el de buena fe.

De la misma manera, el principio de que tratamos no es aplicable a las relaciones contractuales (STS de 23 de febrero de 2001). No ya porque la ley reconozca a la Administración también un ius variandi (mucho más limitado) en el caso de los contratos administrativos, sino porque, al margen de este supuesto, cuando alguna de las partes, ya sea la Administración o el contratista, no se atiene a los compromisos acordados, lo que se produce es sencillamente un incumplimiento del contrato, convenio o concierto. Lo que hay que aplicar al respecto es la doctrina del negocio jurídico y no otra cosa, tanto en Derecho privado como público ${ }^{12}$. Sí puede atentar en cambio contra los «actos

${ }^{12}$ Como señala GARCía DE ENTERRíA, op. cit., p. 72, el criterio fundamental de la doctrina «radica justamente en imponer una vinculación sin haber mediado consentimiento negocial». En el mismo sentido, GonZÁlEZ PÉREZ, op. cit., p. 119. 
propios» quien pretende la anulación en vía judicial de acuerdos alcanzados mediante la libre manifestación de su voluntad negocial. Aunque sobre este concreto problema volveremos luego.

Por lo que se refiere a los actos administrativos en sentido estricto, es muy discutible que haya una relación directa entre la doctrina de los actos propios y el principio de irrevocabilidad de los actos administrativos favorables. Aunque algunas decisiones judiciales que lo afirman se expliquen por la traslación mecánica de la dogmática civilista al Derecho público (tanto más frecuente cuanto menor es la especialización del Juez contencioso-administrativo), la irrevocabilidad de los actos administrativos favorables, que es en todo caso relativa, constituye en realidad una excepción a las facultades de autotulela de que goza la Administración para la defensa de los intereses públicos, excepción que se basa en el principio de seguridad jurídica y en la garantía de las situaciones jurídicas de los ciudadanos ${ }^{13}$. Cosa distinta es también que el ejercicio de las facultades de revisión de oficio de los actos favorables deba atemperarse en virtud del principio de buena fe (art. 106 de la LRJPAC) y del de confianza legítima (art. 3 de la misma Ley). Pero invocar los «actos propios» en estos supuestos no es adecuado, cuando la propia Ley reconoce las facultades revisoras de la Administración. La cuestión está en si se han superado o no, en el caso concreto, los límites legales de la revisión de oficio (o de la declaración de lesividad y la posterior impugnación de los actos), una cuestión que debe resolverse en aplicación del principio de legalidad y, en su caso, del de buena fe y confianza legítima, sin que la doctrina de los actos propios aporte nada en este supuesto. La invocación de esta doctrina para enjuiciar la conformidad o no a Derecho de un acto de revisión de otro anterior no deja de ser puramente retórica.

Tampoco es correcto aplicar la regla de prohibición del venire contra factum proprium cuando la Administración se aparta de sus precedentes en las relaciones con otros sujetos. Como ha señalado desde hace tiempo la doctrina ${ }^{14}$, la separación del precedente debe enfocarse en Derecho desde la perspectiva del derecho a la igualdad, pues el precedente administrativo no vincula a la Administración, pero sería contrario al principio de igualdad separarse del mismo sin una justificación objetiva y razonable.

Otra cosa es que la Administración adopte en un caso concreto una decisión incompatible con otra anterior, es decir, con un prece-

${ }^{13}$ Es la tesis de GARCÍA DE ENTERRÍA en el estudio de 1956 citado, tesis que recoge, por ejemplo, R. BOCANEGRA, hoy en Lecciones sobre el acto administrativo, Madrid, 2002, p. 201 y también J. GARCía LuENGO, op, cit., p. 131.

${ }^{14}$ L. Ma . DíEZ-PiCAZO, «La doctrina del precedente administrativo», $R A P, 98,1982$, pp. 7 y ss. También en relación con la doctrina de los actos propios, GONZÁLEZ PÉREZ, op. cit., pp. 123-124. 
dente, que haya adoptado respecto del mismo sujeto (por ejemplo, denegar repentinamente un año una pensión o subsidio que se venía concediendo, sin cambio de las circunstancias), pues en tal caso no es aplicable, obviamente, el principio de igualdad, que hace referencia a las diferencias de trato que la Administración dispensa a distintos sujetos. Entonces si es aplicable la doctrina de los actos propios ${ }^{15}$, si bien no siempre determinará la antijuridicidad del cambio de criterio, pues el precedente puede ser ilegal y ese cambio de criterio estar justificado y fundamentado.

De la misma manera, que la Administración se aparte en un caso concreto de lo previsto por circulares o instrucciones propias constituirá una infracción del principio de legalidad, en el caso de que aquéllas tengan eficacia normativa, o bien del de igualdad, si supone desigualdad de trato, o del de interdicción de la arbitrariedad, en la medida en que las circulares internas se consideren vinculaciones establecidas por la propia Administración para el ejercicio de sus potestades discrecionales. Tampoco aquí la invocación de los actos propios tiene un sentido preciso y efectivo.

Por último, alegar infracción de los actos propios cuando la Administración no tiene en cuenta al decidir su respuesta previa a una consulta no vinculante o el contenido de un acto de certificación o lo que se deduce de un acto previo de trámite (informes, pruebas, actas ...) tampoco es procedente, pues no nos encontramos en este caso con ningún «acto propio» a los efectos que aquí importan, no pudiendo trasladarse al Derecho administrativo imágenes y supuestos que podrían tener otra significación jurídica en las relaciones jurídico-privadas.

Hechas estas aclaraciones, a modo de ejemplo, es necesario profundizar en los requisitos de aplicación de la doctrina de los actos propios.

\section{REQUISITOS PARA LA APLICACIÓN DE LA DOCTRINA DE LOS ACTOS PROPIOS}

La correcta aplicación de la regla que veda ir contra los actos propios presupone la existencia de a) un determinado tipo de «acto» $\mathrm{o}$ conducta; b) que pueda ser considerado como "propio»; y c) una actuación posterior del mismo sujeto contradictoria e incompatible con aquél. Veamos ahora más detenidamente estos tres elementos.

${ }^{15}$ GONZÁlez PÉREZ, op. et loc. ult. cit. 


\section{EL «ACTO» O CONDUCTA: ELEMENTO OBJETIVO}

La doctrina jurídica suele señalar que se trata aquí de una «conducta» más que de un acto en sentido estricto ${ }^{16}$. Es decir, de un comportamiento que revele la actitud que el sujeto autor del acto ha observado en determinada relación jurídica, creando una determinada situación con efectos jurídicos y generadora de confianza en su respeto y mantenimiento.

Esa «conducta» puede venir constituida por un conjunto de actuaciones concurrentes o continuadas -y éste es el supuesto más característico de aplicación de la regla- o por un solo acto previo, siempre que sea revelador de una conducta ${ }^{17} \mathrm{y}$, por tanto, no extraordinario, ocasional o anormal. Puede tratarse de actuaciones o manifestaciones expresas, caso en el que es más claro afirmar la presencia del «acto propio», pero puede tratarse igualmente de un acto tácito o de una actitud de consentimiento tácito de ciertas situaciones.

En este último caso, el problema consiste en determinar si a través de ella el sujeto que después observa una conducta contraria ha querido efectivamente consentir una situación jurídica y si ello tiene efectos autovinculantes. En la práctica la respuesta de los jueces y tribunales varía. Por lo general, son menos proclives a admitir como acto propio una conducta pasiva de la Administración (inactividad, incluso tolerancia de facto) que de los ciudadanos (consentimiento tácito por no haber recurrido contra actos cualificados: bases de convocatorias, pliegos de cláusulas, típicamente). Ahora bien, esta actitud se justifica también porque la expresión de la voluntad de la Administración exige unos requisitos formales - de procedimiento, de manifestación- que no se precisan en la manifestación de voluntad de los sujetos privados.

En todo caso, para que una conducta se considere vinculante en aplicación de la doctrina de los actos propios debe reunir algunas condiciones.

a) Ha de tratarse de una conducta susceptible de producir efectos jurídicos en relación con el sujeto que exige el respeto de los actos propios. Es decir, ha de tratarse de actos o comportamientos capaces de crear, modificar o extinguir situaciones jurídicas. Así lo afirma la doctrina mencionada y la jurisprudencia con carácter general.

De ahí que, por regla general, no son «actos propios», a estos efectos y tratándose de actuaciones administrativas, los informes previos evacuados en el expediente, salvo que sean vinculantes; las consultas previas evacuadas sobre la misma cuestión en que recae un acto decisorio contrario, salvo cuando tienen también carácter vinculante se-

${ }^{16}$ GARCÍA DE ENTERrÍA y GONZÁLEZ PÉREZ, ops. ult. cit.

${ }^{17}$ Ibidem. 
gún la ley, como es natural; los actos de trámite, salvo que revelen una manifestación de voluntad definitiva (lo que puede ocurrir) generando confianza en el mantenimiento de una situación; las meras declaraciones informales de la Administración o sus autoridades y agentes sin eficacia jurídica alguna; las certificaciones expedidas a efectos distintos que declaran la veracidad de hechos después desconocidos o negados en virtud de otras pruebas o actuaciones, sin perjuicio de la responsabilidad en que pueda incurrir la Administración certificante y a salvo casos concretos en que la certificación es reveladora de una conducta o posicionamiento de la Administración contradicho posteriormente ${ }^{18}$.

Por lo general, pues, tratándose de actos de la Administración se ha de tratar de actos definitivos, aunque hay excepciones. Lógicamente estamos hablando también de actos favorables para quien alega la existencia de los «actos propios», aunque sean desfavorables para terceros (por ejemplo, el otorgamiento de una licencia urbanística a quien se había denegado previamente, impugnada por un vecino perjudicado).

b) En segundo lugar, el «acto» o conducta debe ser concreto y revelador a las claras de la voluntad del sujeto que lo adopta. Como señala la jurisprudencia que hemos examinado, el acto o conducta que se predica como «propio» debe definir de manera indubitada, concluyente y clara una conducta creadora de una situación jurídica. No basta, por tanto, con invocar como acto propio conductas ambiguas, confusas o indefinidas, que puedan prestarse a distintas interpretaciones.

Esto supone, en relación con los actos administrativos posteriores, la improcedencia de considerar «actos propios» las conductas previas y contrarias meramente pasivas o de ambigua tolerancia. Así, por ejemplo, no implica venire contra factum proprium la decisión de un Ayuntamiento de empezar a liquidar tributos locales por actividades y propiedades integradas en una base militar cuando hasta entonces ha observado una total inactividad al respecto, pues esa inactividad no puede condicionar el ejercicio de sus facultades de gestión tributaria (STS de 23 de octubre de 1999). Lo mismo puede decirse de decisiones administrativas que ponen fin en un momento determinado a situaciones, a veces muy anteriores, de mera tolerancia, como es el caso de las usurpaciones de la zona marítimo-terrestre sin ningún título jurídico (STS de 15 de marzo de 1999).

${ }^{18}$ Así, por ejemplo, STS de 20 de febrero de 1992, según la cual va contra los actos propios el Ayuntamiento que niega a una persona su condición de residente en el municipio a efectos de inadmitirla en un concurso para adjudicar la explotación de un bar de las instalaciones deportivas municipales, cuando dicha persona figura inscrita como tal en el padrón municipal. 
No está claro, sin embargo, que los órganos judiciales apliquen el mismo rasero cuando se trata de acto de los ciudadanos en sus relaciones con la Administración.

c) $\mathrm{El}$ «acto propio» debe reunir también la nota de voluntariedad o espontaneidad y no tratarse de un acto impuesto o forzado. Este requisito tiene especial importancia cuando se refiere a actos de los ciudadanos. De ahí, por ejemplo, que algunas sentencias no consideren actos propios la aceptación, tácita y aún expresa, por los interesados de ciertas obligaciones ilegales impuestas por la Administración, que condicionan el ejercicio de sus derechos (pago de reparcelaciones económicas o derechos de aprovechamiento inexistentes para obtener licencia: STS de 23 de octubre de 1991 y 28 de septiembre de 2001). En efecto, si el acto propio implica una manifestación de consentimiento, resulta difícil aplicar la regla cuando el ciudadano se ve prácticamente impelido a observar una conducta con la que no está de acuerdo para obtener un derecho que le corresponde. Pero hay que reconocer que la jurisprudencia no es unánime al respecto ${ }^{19}$.

Prueba de ello es la habitualidad con que los órganos judiciales aplican la doctrina de los actos propios (y del acto consentido) para rechazar la impugnación de las resoluciones de oposiciones y concursos o de procedimientos de adjudicación de contratos fundadas en la no impugnación previa y tempestiva de las bases de la convocatoria o de los pliegos de cláusulas. Si alguna apertura ha existido recientemente al respecto, como veremos, se funda en consideraciones de legalidad, pero no en la ausencia de consentimiento voluntario de quien no recurrió las bases o los pliegos. Y, sin embargo, en estos supuestos la solución fundada en el principio de la autonomía de la voluntad puede no ser acertada, pues el opositor, el concursante, el empresario ofertante están ante la Administración y en el momento de decidir si recurrir o no contra las bases o pliegos en una situación de inferioridad. Si recurren las bases o pliegos, por entenderlos contrarios a Derecho, las posibilidades de satisfacer sus expectativas pueden retrasarse o quedar perjudicadas de hecho. En consecuencia, en la decisión implícita de no recurrir previamente contra las bases o pliegos no siempre hay plena voluntariedad, de la misma manera que no se puede imputar siempre mala fe a quien la adopta y más tarde impugna la resolución del procedimiento con base en la ilegalidad de la convocatoria supuestamente «consentida».

Esa situación de desigualdad entre los sujetos de la relación jurídica debería tenerse en cuenta cuando se aplica una regla como la del

${ }^{19}$ Sobre ello, F. Velasco Caballero, op. cit, , p. 251-252. Se pregunta el autor si es aplicable en estos casos la regla volenti non fit iniuria, cuando hay una presión administrativa (o económica) y «cuando al particular, en realidad, no le queda otra opción que consentir una cláusula contra sus derechos e intereses». 
venire contra factum proprium que tiene su origen y justificación en las relaciones entre sujetos formalmente iguales, típicas del Derecho privado.

Desde otro punto de vista, la exigencia de voluntariedad del acto propio supone no considerar como tales las actuaciones realizadas en virtud de un vicio de la voluntad: error, dolo, fraude, maquinaciones insidiosas. Por ejemplo, una STS de 18 de mayo de 1999 rechaza aplicar la doctrina de los actos propios a declaraciones de la Administración realizadas con lo que denomina «reserva mental», que no es, en esa Sentencia, sino la actuación dolosa del interesado que confunde a la Administración provocando un acto erróneo ${ }^{20}$.

\section{El CARÁCTER «PROPIO» DEL ACTO: ELEMENTO SUBJETIVO}

La jurisprudencia, según se viene diciendo, aplica la prohibición de ir contra los actos propios tanto a la Administración como a los particulares que con ella se relacionan. Conviene distinguir ahora los dos supuestos.

a) Cuando se trata de actos propios de la Administración, la misma queda vinculada sin perjuicio de que sea distinta la persona o personas jurídicas que adoptaron las conductas previas y las posteriores contradictorias. También queda vinculada por la actuación de sus mandatarios y agentes o por la de las Administraciones a las que ha sucedido en el ejercicio de una competencia ${ }^{21}$.

Sobre estas premisas no debe caber duda, si se parte de la premisa de la personalidad jurídica única de cada Administración, a la que se imputan sus actos como a un todo, así como de que los deberes vinculados a la buena fe, incluido el de no operar contra los actos propios, son transmisibles junto con la competencia implicada.

Sin embargo, es dudoso que los actos de un determinado órgano de la Administración, de la misma Administración, produzcan siempre ese efecto vinculante respecto de otros órganos con competencia funcional distinta. No es eso lo que se deduce de la jurisprudencia, como demuestran algunos ejemplos típicos. Según una STS de 4 de julio de 1992, el abono de la tasa por la concesión de una licencia, no

\footnotetext{
${ }^{20}$ En el caso, el recurrente había confundido a la Administración tributaria, al presentar sus autoliquidaciones simulando que no existía un requerimiento previo de la Inspección para que lo hiciera, con el fin de evitar la imposición de sanciones (art. 30.2.b. del Reglamento de Inspección), de manera que la Administración, partiendo del hecho simulado, las aceptó, pero posteriormente comprobó la actuación inspectora y el requerimiento dictando nueva resolución con imposición de sanciones.

${ }^{21}$ En todo ello insiste el artículo de L. LóPEz RoDó antes citado, con precisiones que, cincuenta años después, nos pueden parecer obvias.
} 
objetado por la Administración, no implica de por sí la concesión de la licencia ni vincula positivamente al órgano competente para otorgarla. Otra STS de 4 de abril de 2001 rechaza que se deba reconocer como suelo urbano en aplicación de la doctrina de los actos propios un determinado terreno por el hecho de que se haya venido tributando por él como tal a efectos del impuesto de plusvalías y se hayan venido satisfaciendo las tasas de agua, basuras y alcantarillado. Según se declara en ella,

«...en esta materia, la jurisprudencia del Tribunal Supremo no aplica en absoluto la doctrina de los actos propios, sin duda por el carácter reglado del suelo urbano, que impide que tal clasificación se adquiera por actos presuntos, tácitos o indirectos distintos del único dato que importa, a saber, que el suelo cuente con los servicios y que se encuentre en la malla urbana (Sentencias del Tribunal Supremo de 19 de diciembre de 1996, 3 de mayo de 1995 y 16 de febrero de 1993, según las cuales el pago de impuestos o tasas no atribuye a los terrenos la clasificación de urbanos)».

En realidad y aparte las matizaciones que impone la aplicación estricta del principio de legalidad, de las que trataremos más adelante, lo que de esta doctrina se deduce es que no es «acto propio» vinculante el que ha sido adoptado con una finalidad distinta y en el marco de relaciones jurídicas materialmente diferentes del que se considera infractor de la regla. Por eso la actuación de determinados órganos, sectores, áreas o departamentos administrativos no vincula a otros. La unicidad de la personalidad jurídica administrativa tiene sus límites, pues es contrario a la realidad (y a la capacidad de la Administración) exigir siempre un comportamiento coherente de los distintos departamentos entre sí, lo que implicaría una comunicación constante que no existe ni es fácil de organizar. Aquí constatamos uno de esos límites. No se puede presumir jurídicamente una coordinación tan perfecta de la Administración que imponga la vinculación de unos servicios por la acción de otros. Si así fuera, las posibilidades del interesado de sortear la aplicación de la legalidad que le incomoda se ampliarían notablemente. Efecto contrario al que debe pretender la aplicación de un principio que se funda en el de buena fe.

Por otra parte, y con mayor razón, no se puede invocar como acto propio el de otra Administración que ejerce competencias concurrentes sobre el mismo objeto. El otorgamiento de una licencia urbanística municipal no vincula, por ejemplo, a la Administración estatal o autonómica que ha de conceder concesión autorización para ocupar terrenos de dominio público o sometidos a servidumbres o limitaciones de uso para protegerlo (zonas de policía, de afección, de protección...) y viceversa. 
b) Si la regla venire contra factum proprium non valet se aplica a la conducta de particulares, debe verificarse que se trata de la misma persona, física o jurídica, o de sus causahabientes o representantes, salvo que se trate de actuaciones personalísimas que sólo vinculan a quien las haya realizado por sí mismo.

Aquí no se plantean los problemas a que se ha hecho referencia en el párrafo anterior, incluso si se trata de personas jurídicas con organización compleja, siempre claro está que la voluntad social se haya formado y manifestado conforme a Derecho.

En la práctica, la doctrina de los actos propios se aplica con mayor rigor y con menos matices y excepciones cuando se trata de actos de los particulares que cuando se refiere a actuaciones de la Administración. Es en cierto modo lógico, pues la Administración se rige por el principio de legalidad esencialmente, sin olvidar otros principios y dejando ahora de lado las precisiones, mientras que los particulares se rigen fundamentalmente por el principio de autonomía de la voluntad también en sus relaciones con la Administración. No obstante, hay que volver a insistir en que la desigualdad de las partes de la relación jurídica típica del Derecho administrativo invita a considerar que en muchos casos el consentimiento del particular, aunque no obligado, si es al menos inducido por las consecuencias desfavorables que pueden derivar de su ausencia, así como que existen derechos irrenunciables, frente a los que no es lícito alegar actos propios en contrario o el consentimiento presunto del interesado. Volveremos inmediatamente sobre el argumento.

\section{LA ACTUACIÓN CONTRADICTORIA Y SUS CONSECUENCIAS JURÍDICAS}

Por último, debe existir una actuación contradictoria o incompatible con los «actos propios» que se invocan por quien quiere atacar u oponerse a aquélla. Esa actuación puede ser cualquiera, siempre que se demuestre su incompatibilidad con las conductas anteriores y que esa contradicción crea en el sujeto que la sufre una situación contraria a las exigencias de la buena fe y de la seguridad jurídica.

Naturalmente, se trata de actuaciones contrarias al sentido objetivo de los actos propios y no al sentido que subjetivamente pretenda darles quien se vale de la regla que analizamos.

En realidad, las conductas contradictorias pueden clasificarse en dos grupos, las que suponen adoptar una decisión de cualquier tipo, con eficacia jurídica propia, o las que consisten en una pretensión procesal incompatible con la conducta sustantiva anterior del sujeto que la deduce.

En el primer caso se trata sobre todo de actos de la Administración, de carácter desfavorable (para quien alega la regla), ya sean ex- 
presos o presuntos, actuaciones en vía de hecho o incluso situaciones de inactividad. Pero también pueden ser actos de los particulares (renuncia a un puesto de trabajo, incumplimiento de una condición aceptada).

Las pretensiones procesales contrarias a los actos propios son sobre todo de los particulares, pues la Administración podrá resolver normalmente por sí misma en virtud de la autotutela. Pero a veces se trata también de pretensiones procesales de la Administración incompatibles con su propia actuación. Por ejemplo, si se pretende en vía procesal endurecer el acto administrativo impugnado en contra del recurrente, o cuando la Administración pretende la inadmisibilidad del recurso después de haber confundido al recurrente sobre los recursos a interponer. En consecuencia, puede tratarse de pretensiones contradictorias tanto de inadmisibilidad como de estimación o desestimación del recurso.

La conducta contradictoria con los actos propios, para que se considere contraria al ordenamiento, debe carecer de una justificación suficiente, a la luz no ya del principio de legalidad sino del de buena fe. La justificación que permite contradecir lícitamente conductas anteriores puede ser de distinto tipo, ya se funde en un cambio de las circunstancias objetivas o en la válida adopción de nuevos criterios de actuación administrativa. Pero, tratándose de actuaciones de la Administración, resulta necesario que exista una motivación expresa. Así se deduce de una interpretación amplia de lo dispuesto en el artículo 54.1.c) de la LRJPAC.

Las consecuencias de la aplicación de la doctrina de los actos propios a las referidas actuaciones contradictorias son fáciles de deducir. Si se trata de una decisión administrativa habrá que declarar su ilegalidad por contraria al principio de buena fe o confianza legítima, lo que implicará su anulación total o parcial con las demás consecuencias jurídicas que procedan en cada caso (restablecimiento de situaciones jurídicas, reconocimiento de derechos, medidas indemnizatorias...).

Si se trata de una pretensión procesal contraria a los actos propios procede su rechazo, bien aplicando una causa de inadmisibilidad si concurre -muy en particular la del acto consentido, como es frecuente-, bien mediante la desestimación del recurso. En cualquier caso, la declaración de que la pretensión procesal es contraria a los actos propios de quien la deduce excusa al juzgador de contrastar la legalidad del acto recurrido, de manera que opera como una causa obstativa del examen del verdadero fondo del asunto. Esta circunstancia debe valorarse en atención al principio pro actione, que puede quedar sustancialmente afectado, lo que no significa necesariamente conculcado. Quizá por eso en muchas ocasiones el principio venire contra factum 
proprium non valet no constituye la razón única de la decisión judicial, sino un fundamento complementario de otros. Excepto, ciertamente, cuando se aplica la causa de inadmisibilidad del acto consentido, por considerar que el recurrente se aquietó -acto propio- ante actos que podía y debería haber recurrido en otro momento anterior.

\section{ACTOS PROPIOS Y PRINCIPIO DE LEGALIDAD DE LA ADMINISTRACIÓN}

Ya se ha dicho antes, con palabras del Tribunal Constitucional, que la doctrina de los actos propios no puede ser aplicada en el Derecho público sin muchos matices. A lo largo de estas páginas se han señalado algunos. Pero los más importantes son los que derivan del principio de legalidad. No porque este principio no rija también en el Derecho privado. Antes al contrario, también en este último ámbito se aplica la regla posse quemlibet contra actum a se gestum venire quando actus esset ipso iure nullus. Sino porque la función y el alcance del principio de legalidad es distinto y mucho más intenso en el Derecho administrativo.

La cuestión reside en saber, en primer término, si la Administración está vinculada por sus actos propios que han generado una situación de confianza cuando esos actos o el respeto a sus consecuencias supone realizar actuaciones contrarias a la ley o al Derecho. Pero también se plantea el dilema opuesto, esto es, si el deber del particular de atenerse a sus propios actos impide el restablecimiento de la legalidad administrativa eventualmente vulnerada en su perjuicio.

La primera de estas dos cuestiones supone analizar las relaciones entre el principio de legalidad y los de buena fe (o confianza legítima) y seguridad jurídica en el Derecho administrativo. La respuesta a esta cuestión, que en términos generales desborda el objeto de este concreto trabajo, no está clara, pues oscila entre la idea de primacía absoluta de la legalidad y de la plena vinculación a ella de la Administración, por un lado, y la utilización de aquellos otros principios como elementos de flexibilidad o templanza en la aplicación de la legalidad estricta, cuando puede llevar a resultados injustos o inicuos.

Puede decirse, no obstante, que la jurisprudencia, tampoco unánime, se inclina por dar prioridad al principio de legalidad cuando se trata de resolver un recurso contra decisiones de la Administración que pueden contradecir actos propios. Valga por todas y por la claridad de su doctrina la Sentencia del Tribunal Supremo de 26 de febrero de 2001 (Pte.: Rafael Fernández Montalvo):

«Tanto la doctrina del Tribunal Constitucional como la jurisprudencia de este Alto (cfr. STS de 1 de febrero de 1999) considera que el 
principio de buena fe protege la confianza que fundadamente se puede haber depositado en el comportamiento ajeno e impone el deber de coherencia en el comportamiento propio. Lo que es tanto como decir que dicho principio implica la exigencia de un deber de comportamiento que consiste en la necesidad de observar de cara al futuro la conducta que los actos anteriores hacian prever y aceptar las consecuencias vinculantes que se desprenden de los propios actos, constituyendo un supuesto de lesión a la confianza legitima de las partes 'venire contra factum proprium'. Ahora bien, este principio no puede invocarse para crear, mantener o extender en el ámbito del Derecho público, situaciones contrarias al ordenamiento jurídico, o cuando el acto precedente resulta una contradicción con el fin o interés tutelado por una norma jurídica que, por su naturaleza, no es susceptible de amparar una conducta discrecional por la Administración, que suponga el reconocimiento de unos derechos y/u obligaciones que dimanen de actos propios de la misma. O dicho en otros términos, la doctrina invocada de los 'actos propios' sin la limitación que acaba de exponerse podría introducir en el ámbito de las relaciones de Derecho público el principio de la autonomía de la voluntad como método ordenador de materias reguladas por normas de naturaleza imperativa, en las que prevalece el interés público salvaguardado por el principio de legalidad; principio que resultaría conculcado si se diera validez a una actuación de la Administración contraria al ordenamiento jurídico por el solo hecho de que así se ha decidido por la Administración o porque responde a un precedente de ésta».

En resumen, no cabe oponer actos propios a legalidad o, en otros términos, sólo es aplicable el principio que ahora examinamos en el ámbito de las actuaciones no regladas, puramente discrecionales. Ésta es la doctrina que comparten, de manera explícita o implícita, la mayor parte de las sentencias que abordan la cuestión ${ }^{22}$. Desde luego, puede entreverse en otras sentencias un planteamiento en parte diferente (incluso contrario). Pero normalmente no son sentencias que contrapongan en su fundamentación legalidad y actos propios para llegar a conclusiones doctrinales opuestas. Son sentencias que, por lo general, ni siquiera se plantean o no se plantean claramente si la actuación contraria a los actos propios es o no conforme a la legalidad objetiva. Con todo, la primacía del principio de legalidad es amplia-

${ }^{22}$ Por ejemplo, SSTS de 15 de marzo de 1999, 2 de octubre de 2000, 5 de junio de 2001 ... Como declara la última citada, la doctrina de los actos propios «no puede invocarse para crear, mantener o extender, en el ámbito del Derecho público, situaciones contrarias al ordenamiento jurídico, o cuando el acto precedente resulta una contradicción con el fin o interés tutelado por una norma jurídica que, por su naturaleza, no es susceptible de amparar una conducta discrecional». 
mente sostenida por la jurisprudencia. No tanto quizá por la doctrina jurídica, que introduce algunos matices ${ }^{23}$.

Cuestión distinta es si el principio de legalidad prevalece también frente a los actos propios de los particulares. En este caso el problema se plantea en distintos términos, puesto que la situación que puede ser contraria a la buena fe y a la seguridad jurídica la crea el particular y no la Administración, siendo así que aquél actúa (o deja de actuar) en virtud del principio de autonomía de la voluntad. Entonces el contraste con el principio de legalidad no es tan frecuente ni depara los mismos resultados. Los órganos judiciales pueden presumir que el recurrente era libre de aceptar o no las condiciones que le fueron impuestas por la Administración para crear una situación jurídica a su favor y que después pretende impugnar, declinando en consecuencia analizar si tales condiciones son o no conformes a Derecho. También suelen considerar que quien adoptó la libre decisión de no impugnar las bases de una oposición o concurso o unos pliegos de cláusulas particulares y las reglas de selección del contratista (o actos similares) no puede fundar en su ilegalidad el recurso contra el acto que pone fin al correspondiente proceso selectivo, máxime cuando en estos casos suele haber terceros interesados, que pueden resultar perjudicados por la revisión judicial. Éstos sí que son planteamientos judiciales casi unánimes, que dan al traste con gran número de recursos sin examinar siquiera la legalidad de la actuación administrativa que en realidad se impugna.

Tales planteamientos responden, por lo demás, a una concepción subjetiva del proceso contencioso-administrativo, como proceso entre partes, que excluye o reduce a un lugar muy secundario la función de control objetivo de la legalidad que el juez debe desempeñar a través del mismo, concepción unívoca aquélla y hoy dominante entre nosotros, que está impregnada de influencias privatistas. De hecho, sólo desde una perspectiva opuesta puede darse prioridad al enjuiciamiento de la legalidad del acto pasando por encima de las decisiones formalmente propias, aunque no siempre libres en realidad, de los particulares recurrentes. Afortunadamente hay excepciones a la regla, que tienen en cuenta esos elementos de legalidad objetiva.

De algún fallo en contrario da cuenta GONZÁlEZ PÉREZ en su libro sobre la buena $\mathrm{fe}^{24}$, considerándolo muestra de «la correcta doctri-

${ }^{23}$ Así GONZÁLEZ PÉREZ, op. cit., para quien el «acto propio» debe tener eficacia jurídica y ser válido, como regla general, aunque se pregunta también hasta qué punto la confianza creada por la Administración en un determinado sentido no comporta consecuencias jurídicas (p. 123).

${ }^{24}$ STS de 9 de mayo de 1995 (Pte.: Ponce de León), relativa a la impugnación de los pliegos de la contratación administrativa no recurridos en su momento y si al impugnar el acto de adjudicación. La Sentencia entiende que en el caso contemplado no puede sostenerse 
na». En su opinión sólo los actos jurídicamente válidos pueden producir los efectos de la doctrina de los actos propios y de ahí que no le parezca buena doctrina la que «sin distinguir en orden a la validez de los mismos, declara que la no impugnación de los mismos impide la impugnación de los posteriores. Así, los pliegos de la contratación administrativa». Pero esta argumentación confunde la validez del acto no impugnado o consentido con la validez de la conducta del interesado al consentirlo, que es lo que en estos casos se considera «acto propio».

La clave está, por el contrario, en entender que, a pesar del presunto consentimiento tácito del interesado, el órgano judicial puede controlar la legalidad del acto no impugnado, al menos en ciertos casos. Esta posibilidad, que tiene como fundamento último el que le da la propia Sentencia de 9 de mayo de 1975 citada por GonZÁlez PérEZ, reaparece ahora en cierta jurisprudencia del Tribunal Supremo que declara que la doctrina de los actos propios «puede ceder cuando los vicios denunciados son constitutivos de nulidad de pleno derecho». Así, SSTS de 9 de febrero de 2001 y 19 de marzo de 2001 (Pte.: Trillo Torres), ambas relativas a la impugnación de la adjudicación de contratos fundada en la nulidad del pliego de cláusulas no recurrido en su momento.

De hecho, como suele decirse, la nulidad de pleno derecho constituye un vicio de orden público del acto administrativo y no es convalidable ni subsanable. Más aún, los actos posteriores del procedimiento de adjudicación no son realmente «independientes» de la aprobación del pliego, de manera que no puede decirse que la nulidad de éste no se transmita a la resolución final de adjudicación. Esta consideración facilita un control «objetivo» de legalidad pasando por encima de la doctrina de los actos propios. Especialmente tratándose de pliegos de cláusulas o bases de las convocatorias de concursos y oposiciones u otros procedimientos en concurrencia, que no dejan de ser actos de trámite, aunque cualificados e impugnables directamente, respecto de los que presumir el consentimiento de los concursantes disconformes no deja de ser una consideración ajena a la realidad en muchos casos.

También el Tribunal Constitucional en algunas Sentencias se ha apartado de la jurisprudencia tradicional que impide cuestionar las ba-

\footnotetext{
«la reiterada doctrina jurisprudencial, de que la aceptación de las condiciones del pliego y el consentimiento prestado a la convocatoria impiden la impugnación del concurso, pues este poder de atracción vinculante sólo puede admitirse cuando exista una adaptación a la normativa aplicable, mas no en cambio cuando según sucede en el presente supuesto, se incurre en omisiones o defectos sustanciales que afectan a su validez, ya que entonces se está por encima de los intereses personales y ello obliga tanto al Ayuntamiento que convocó el concurso como a quienes a él acuden y por consiguiente su enmienda o corrección no dependen de la voluntad de las partes, sino del propio juzgador, que ha de revisar los actos de la Administración pública para así velar por la integridad y pureza de la actuación de la misma».
} 
ses de los concursos no impugnadas en su día al recurrir contra el acto definitivo del procedimiento selectivo. Pero ello en los supuestos (lógicos tratándose de Sentencias resolutorias de recursos de amparo) de que las bases sean contrarias a los derechos fundamentales (en concreto al de igualdad en el acceso a las funciones públicas en los casos contemplados, art. 23.2 CE). Así, SSTC 193/1987, de 9 de diciembre, 200/1991, de 28 de octubre y (en ésta con toda rotundidad) 93/1995, de 19 de junio ${ }^{25}$. En ellas el Tribunal desestima la excepción de acto consentido relativa a la no impugnación previa de las bases por entender que la lesión del derecho fundamental, derivada de ellas, es imputable también y de manera concreta al acto resolutorio del procedimiento. Lo mismo podría decirse de otros procedimientos en concurrencia (contratos, ayudas, concesiones y autorizaciones), en los que puede infringirse el derecho constitucional de igualdad (art. $14 \mathrm{CE}$ ).

Esta doctrina es correcta, si se tiene en cuenta no sólo la dudosa voluntariedad del «consentimiento» de las bases o pliegos o condiciones generales, cuando ya colocan al recurrente en una situación no favorable, sino particularmente el carácter preferente (e irrenunciable) que los derechos fundamentales tienen en nuestro ordenamiento constitucional. La protección reforzada de éstos, su carácter de fundamento del orden político y la nulidad radical de los actos que los infringen quedan desvirtuados cuando se inadmite o desestima una pretensión procesal dirigida contra el acto definitivo que consuma su infracción sobre la base del supuesto consentimiento del acto de trámite inicial y en aplicación de la doctrina de los actos propios, argumentos de naturaleza formal las más de las veces.

Si la legalidad debe primar sobre los actos propios, así debe ser también cuando el venire contra se aplica a actuaciones de los ciudadanos, al menos cuando no hay una manifestación de voluntad expresa y consciente y no se advierte mala fe. Sobre todo, si la aplicación de la doctrina de los actos propios supone mantener la nulidad absoluta de un acto administrativo o una infracción de derechos fundamentales.

\section{PARA TERMINAR}

Como puede verse, la antigua doctrina de los actos propios sigue estando presente en la realidad de nuestro Derecho administrativo,

${ }^{25}$ La Sentencia estima el recurso dirigido contra el nombramiento de funcionarios del Ayuntamiento de Valencia en virtud de unas bases que primaban irregularmente y en fase de oposición los méritos previos contraídos en el servicio público, bases no recurridas directa e independientemente por los demandantes de amparo. Sobre esta jurisprudencia constitucional, $M^{a}$. J. Alonso MAS, «La modulación de la doctrina del acto consentido en la jurisprudencia del Tribunal Constitucional», REDA, 103, 1999, pp. 451 y ss. 
que es la que deciden que sea los órganos judiciales. Como puede comprobarse, también esa doctrina no siempre se emplea para templar los rigores de la legalidad estricta en el enjuiciamiento de los actos administrativos por razones de seguridad jurídica y buena fe, pues se subordina generalmente al principio de legalidad, pero sí, cada vez más, para no entrar en el fondo de pretensiones dirigidas contra la Administración. Salvo excepciones, las resoluciones judiciales que aplican el principio son poco innovadoras y en muchos casos su invocación en ellas resulta superflua o incorrecta. Hay, bien es verdad, resoluciones judiciales en las que la regla venire contra factum proprium non valet se utiliza como manifestación específica del principio de buena fe o de confianza legítima con toda corrección.

Es posible apreciar también que en estos últimos casos, en los que los «actos propios» son de la Administración y no de los ciudadanos, la regla que aquí comentamos se confunde o se utiliza conjuntamente con el principio de confianza legítima por la jurisprudencia reciente ${ }^{26}$. Ahora bien, este último principio es más propio del Derecho público y, si nos atenemos a la doctrina alemana y a la jurisprudencia del TJCE, de donde lo ha tomado nuestra doctrina y jurisprudencia, tiene un significado más sutil, susceptible de introducir un mayor grado de justicia y equidad en la aplicación del Derecho, de ser correctamente utilizado. De hecho, la doctrina de los actos propios, tal como se utiliza y a pesar de los matices doctrinales, resulta demasiado rígida -o hay «actos propios» o no lo hay- y por eso entra frecuentemente en conflicto con la legalidad en su aplicación práctica. El principio de confianza legítima se funda en cambio en la constatación de una situación normalmente compleja, derivada en muchos casos de actos previos determinados, pero en otros no tanto, sino más bien de comportamientos subjetivos (de una y otra parte de la relación jurídica) que se valoran conjuntamente a la luz de la buena fe y de la seguridad jurídica para lograr una solución que no excluye pero sí modera la aplicación de la ley y el Derecho ${ }^{27}$. De ahí que una evolución deseable de nuestra jurisprudencia, en una línea de perfeccionamiento, pase por manejar más el principio de confianza legítima que la doctrina civilista de los propios actos, aplicada tantas de veces de manera en exceso mecánica.

De otro lado, parece imprescindible aplicar con más cuidado la doctrina de los actos propios cuando se refiere a actuaciones implícitas o tácitas o a presuntos actos consentidos de los ciudadanos, ya que tal como hoy en día se emplea produce en no pocos casos una denega-

\footnotetext{
${ }^{26}$ Por ejemplo, SSTS de 28 de febrero de 1989, 1 de febrero de 1999, etc.

${ }^{27}$ Me remito, lógicamente, a otros trabajos de este número y a la bibliografía citada sobre el principio de confianza legítima, ya que no es el lugar de abordarlo con mayor detalle.
} 
ción material o sustantiva (no formal) de tutela judicial. La jurisprudencia del Tribunal Constitucional y del Tribunal Supremo que hemos examinado ofrece vías para flexibilizar la tradicional posición de nuestros jueces y tribunales en asuntos tan sensibles como la impugnación no directa de las bases de oposiciones y concursos y de los pliegos de cláusulas, en que está en juego el derecho a la igualdad jurídica que -no se olvide- es un derecho de rango constitucional. Estos avances deben aún consolidarse.

Esto sería, repito, lo deseable en la perspectiva de lograr un sistema de Derecho administrativo más justo que el que ahora tenemos. 


\section{DA-2002, núms. 263-264. MIGUEL SÁNCHEZ MORÓN. Venire contra factum propium non valet}

DA-2002, núms. 263-264. MIGUEL SÁNCHEZ MORÓN. Venire contra factum propium non valet 